\title{
A compositional morphosemantic analysis of exclusivity in Ch'ol
}

\author{
Carol-Rose Little \& Mia Wiegand*
}

\begin{abstract}
We argue that novel empirical generalizations on exclusive operators in Ch'ol (Mayan) provide strong evidence for a morphological decompositionality of exclusivity into a core semantic entry and focus sensitivity. There is a robust literature on exclusivity and the distributions of scalar particles in various languages (Beaver \& Clark 2003, 2008; Orenstein \& Greenberg 2010; Coppock \& Beaver 2013, 2011). Coppock \& Beaver (2013) argue that mere operates in a different domain (properties) than only (propositions). Recent work on focus constructions in Mayan languages include Yasavul (2013) for K'iche' and AnderBois (2012) for Yucatec Maya. However, little work has been done on the variation among exclusives in morphologically rich languages like Ch'ol. Original data from fieldwork indicate that exclusivity can occur independently of focus marking, and when divorced from focus, the exclusive morpheme has a wider distribution and range of meanings.
\end{abstract}

Keywords. exclusives; focus; Ch'ol; morphosemantics; Mayan

1. Introduction. In this paper, we provide novel empirical generalizations on exclusive operators in Ch'ol (Mayan). We argue that these empirical generalizations provide strong evidence for a separation of exclusivity into a core semantic entry and focus sensitivity.

The morphemes we focus on in this paper are the focus marker ji $\tilde{n}$ in (1), the exclusive clitic $=j a c h$ in (2), and the bimorphemic jiñ =jach in (3).

(1) Jiñ aj-Maria tsa' jul-i-Ø.

FOC NC-Maria PRF arrive-IV-B3

'[Foc Maria] arrived.' 1,2

(2) Aj-Maria=jach tsa' jul-i.

NC-Maria-=EXCL PRF arrive-IV

'Just Maria arrived.'

\footnotetext{
*We thank the patience of the Ch'ol speakers Little has worked with: Nicolás Arcos López, Celia Alvaro, Paty Arcos Montejo, Morelia Vázquez Martínez, and Virginia Martínez Vázquez. We thank Dorit Abusch, John Bowers, Lauren Eby Clemens, Jessica Coon, Miloje Despić, Molly Diesing, Sarah Murray, Mats Rooth, John Whitman, the Cornell Semantics Group and audiences at the 92nd Annual Meeting of the Linguistic Society of America for comments and discussion. This data was collected during the summer of 2017, partially funded by a grant awarded to Little from the Latin American Studies Program at Cornell and winter 2018, partially funded by the Cornell Graduate School Research Grants awarded to both authors. Unless otherwise marked, all data comes from the authors' fieldwork in Chiapas, Mexico. We use data from both Tila and Tumbalá dialects of Ch'ol. Any errors are our own. Authors: Carol-Rose Little, Cornell University (cr1223@cornell.edu) Mia Wiegand, Cornell University (jrw369@cornell.edu).

${ }^{1}$ Glosses: 1 = first person; 2 = second person; 3 = third person; $\mathrm{A}=$ Set A markers (ergative/possessive); $\mathrm{B}=\mathrm{Set}$ $\mathrm{B}$ markers (absolutive); $\mathrm{CL}=$ classifier; $\mathrm{EXCL}=$ exclusive; $\mathrm{FOC}=$ focus; $\mathrm{IV}=$ intransitive verb; $\mathrm{NC}=$ noun classifier; PREP = preposition; PRF = perfective aspect. Ch'ol uses a Spanish-based orthography: ' $=[2] ; \ddot{a}=[\dot{i}] ; b=[6]$ $\mathrm{ch}=[\mathrm{t} f] ; \mathrm{j}=[\mathrm{h}] ; \tilde{\mathrm{n}}=[\mathrm{n}] ; \mathrm{ty}=\left[\mathrm{t}_{\mathrm{J}}\right] ; \mathrm{x}=[\mathrm{f}] ; \mathrm{y}=[\mathrm{j}] ; \mathrm{C}^{\prime}=$ ejective consonant.

${ }^{2}$ As third person absolutive agreement is null, we do not include it in the glosses.
} 


\section{(3) Jiñ=jach aj-Maria tsa' jul-i. \\ FOC $=$ EXCL NC-Maria PRF arrive-IV \\ 'Only Maria arrived.'}

In this paper, we provide data on the distribution and meaning of these morphemes, which shows their functions as a focus marker (jiñ) and exclusive (=jach).

Exclusives are generally assumed to be quantifiers over propositions taken from an alternative set (usually derived via association with focus) (Rooth 1992). They generally use the schema " $X$ and no more than X". In English, for example, exclusives are operators like only, just, merely, and simply. Beyond the general schema, exclusives can differ in their meaning and distribution. For instance, where just and only are synonymous in (4), they are not in (5).

(4) a. He just has three dogs.

b. He only has three dogs.

(5) a. Your house is just gorgeous!

b. \# Your house is only gorgeous!

In (4) just and only quantify over the numeral three to yield the interpretation that the number of dogs is three and no more than three. However in (5a), just functions as an intensifier on the predicate gorgeous. This is not the same as only in (5b), where only quantifies over the predicate gorgeous to yield the pragmatically odd meaning that your house is gorgeous and no more than gorgeous.

Wiegand (2017, 2018, Forthcoming) proposes a morphosemantic framework to explain the differences between only, just, and merely in English. The main idea is that all exclusives have at least a core exclusive meaning EXCL (given in \$3.1). However, exclusives that are more restricted in meaning and distribution contain (covert) morphosemantic restrictions. So, since only is more restricted than just, only is more complex than just. This analysis can account for the distribution of exclusives in English, but relies heavily on the assumed existence of covert morphological restrictions. However, the pattern of exclusive operators in Ch'ol provides strong empirical evidence for separating the components that contribute to standard notions of exclusivity into smaller morphological units of meaning.

This paper is organized as follows. First, we discuss empirical generalizations and the distribution of $=j a c h, j i \tilde{n}$, and jiñ =jach $(\S 2)$. Then we give background on the compositionality of English exclusives ( 33.1 ). We argue that jiñ is an overt manifestation of a restricting operator (with an added definiteness condition) and =jach carries the exclusive meaning. We provide a derivation for Ch'ol based on Wiegand (2018) in $§ 3.2$. However, for Ch'ol we modify the formalism in order to account for the definiteness restriction coming from the focus marker. We then discuss further evidence in Ch'ol for separating exclusive =jach from focus in $\S 4$. This comes from the use of =jach in emphatic and unexplanatory contexts. Cross-linguistically, we expect other morphologically rich languages to derive exclusives similarly, with variation coming from other selectional requirements. We conclude with some remaining questions and directions for future research with Ch'ol and across other languages $(\S 5)$. 
2. Empirical generalizations on focus and exclusivity in Ch'ol. There has been work on focus in Mayan (Aissen 1992; England 1991) and more recently focus and word order in Ch'ol (Clemens et al. 2017; Little et al. 2016), which we review in $\S 2.1$. However, Ch'ol exclusives have largely gone unreported. We detail new data on exclusives and provide empirical generalizations on the interaction of exclusives and focus in $\S 2.2$.

2.1 FoCUS IN CH'OL. Ch'ol is a predicate-initial, ergative-absolutive, head-marking language. Ch'ol, like other predicate-initial Mayan languages, marks focus syntactically where the focused element surfaces preverbally (Vázquez Álvarez 2011; Aissen 1992; Clemens et al. 2017). ${ }^{3}$ Some Mayan languages, like K'iche', have a designated focus marker (Yasavul 2013); however Ch'ol has an optional focus marker jiñ discussed in detail below. The data in (6) provide examples of unmarked word order (6a), subject focus where the subject is preverbal (6b), and object focus with a preverbal object (6c).

(6) a. VOS (unmarked word order) ${ }^{4}$

Tsa' i-k'ux-u waj aj-Maria.

PRF A3-eat-TV tortilla NC-Maria

'Maria ate a tortilla.'

b. Subject focus

Aj-Maria tsa' i-k'ux-u waj.

NC-Maria PRF A3-eat-TV tortilla

'[Foc Maria ] ate a tortilla.'

c. Object focus

Waj tsa' i-k'ux-u aj-Maria.

tortilla PRF A3-eat-TV NC-Maria

'Maria ate [Foc a tortilla ].'

The focus marker jiñ is optionally used to mark focused constituents (Vázquez Álvarez 2011; 335). For instance, jiñ marks the focused element with subject focus in (7b), as a felicitous response to (7a), and also contrastive subject focus in (8b), in response to (8a).

(7) a. Majki tsa' jul-i?

who PRF arrive-IV

'Who arrived?'

b. Jiñ aj-Maria tsa' jul-i.

FOC NC-Maria PRF arrive-IV

'[Foc Maria] arrived.'

\footnotetext{
${ }^{3}$ See Clemens et al. (2017) for evidence of in situ focus in Ch'ol as well.

${ }^{4}$ When there is an overt determiner with the object, the word order is VSO. See Clemens \& Coon (Forthcoming) and Coon (2010) for more discussion on word order in Ch'ol.
} 
a. Tsa' jul-i aj-Rosa?

PRF arrive-IV NC-Rosa

'Did Rosa arrive?'

b. Ma'añik, jiñ aj-Maria tsa' jul-i- $\varnothing$.

NEG FOC NC-Maria PRF arrive-IV-B3

'No, [Foc Maria] arrived.'

In the examples in (7b) and (8b), the NP has moved to the preverbal focus postion. However, this movement is optional, as shown below in (9) where jin is before the predicate uts'aty 'nice' but targets the noun awotyoty 'your house'.

(9) Jiñ uts'aty aw-otyoty.

FOC nice A2-house

[FOC Your house ] is nice.

Vázquez Álvarez (2011) reports that the particle jiñ is restricted to focused nominals that are definite. ${ }^{5}$ Evidence for this comes from its ungrammaticality when it modifiers the indefinite NP juñ-k'ej waj 'a tortilla' in (10).

* Jiñ juñ-k'ej waj k-om.

FOC one-CL tortilla A1-want

Intended: 'I want [FOC a tortilla ].'

Given jiñ's restriction to definite nominals, it is unsurprising that it is not grammatical with focused numerals (11a) and PPs (11b).

a. * Jiñ juñ-k'ej k-om- $\varnothing \quad$ waj. FOC one-CL A1-want-B3 tortilla.

Intended: 'I want [FOC one] tortilla.'

b. * Jiñ tyi Palenque tsa' k'oty-i- $\varnothing$.

FOC PREP Palenque PRF arrive-IV-B3

Intended: 'He arrived [Foc to Palenque].'

As we will see in the next section, the restrictions we see for jiñ carry over to the morphologically complex jiñ =jach. Furthermore, when =jach occurs without jiñ, it does not exhibit the same kinds of restrictions, despite its similar exclusive interpretation.

2.2 ExClusive PARTICles IN CH' Ol. The morpheme jiñ, as we saw above, focuses definite nominals. In this section, we present the pattern of =jach, a second position clitic glossed as EXCL and the bimorphemic jiñ=jach. Exclusives, such as only, just, merely, and simply, are generally assumed to be quantifiers over propositions taken from an alternative set, usually derived

${ }^{5}$ Indeed, the morpheme jiñi $(j i \tilde{n}+i)$ is a determiner in Ch'ol, however Vázquez Álvarez $(2011 ; 250)$ analyzes it separately from jiñ the focus marker. 
via association with focus (Rooth 1992). They generally contribute their meaning following the schema "X and no more than X".

Evidence for =jach as such an exclusive marker comes from the following data. When answering the question "Who arrived?" in (12) with 'Maria=jach arrived' (12a), it is infelicitous to follow up that answer with (12b) by asserting that someone else arrived too.

(12) Majki tsa' jul-i?

who PRF arrive-IV

'Who arrived?'

a. Aj-Maria=jach tsa' jul-i.

NC-Maria=EXCL PRF arrive-IV

'Just Maria arrived.'

b. \# Yik'oty aj-Rosa tsa' jul-i je'el.

and NC-Rosa PRF arrive-IV also

'And Rosa arrived too.' (Infelicitous after saying (12a))

The clitic $=$ jach attaches to the first prosodic word in the CP layer. In a simplex sentence like (13a) it attaches to the predicate enpermera 'nurse'. It can also attach to the first prosodic word in embedded clauses, like in the relative clause (13b).

a. Enpermera=jach aj-Rosa, mach loktor-ik.

nurse $=$ EXCL NC-Rosa NEG doctor-NEG

Rosa is just a nurse, not a doctor.

b. K-om k-pejk-añ jiñi libro tsa'=jach=bä i-pejk-ä aj-Maria. A1-want A1-read-NML DET book PRF=EXCL=REL A3-read-TV NC-Maria

'I want to read the book that only Maria read.'

Unlike jin in the previous section, which was restricted to definite focused nominals, =jach shows no such distributional restriction. =Jach is licensed as an exclusive over numerals (14a) and PPs (14b), cf. jin in (11).

a. Juñ-k'ej=jach k-om waj. one-CL=EXCL A1-want tortilla.

'I want just one tortilla.'

b. Tyi Palenque=jach tsa' k'oty-i.

PREP Palenque $=\mathbf{E X C L}$ PRF arrive-IV

'He arrived just to Palenque.'

In addition to =jach, exclusivity can also be marked with the the bimorphemic jiñ =jach, analyzed as FOC $=\mathrm{EXCL}$ and translated as 'only' (15a). ${ }^{6}$ The examples in (15) parallel the example in

\footnotetext{
${ }^{6}$ While we are translating =jach and jiñ=jach differently as 'just' and 'only' respectively, in these examples their semantic contribution is identical. The choice to translate them this way has more to do with the overall pattern of distribution than the meaning contributed in this specific instance.
} 
(12) where after asserting 'jiñ=jach Maria arrived' (15a), it is infelicitous to follow up that assertion by saying someone else arrived too in (15b).

(15) Majki tsa' jul-i?

who PRF arrive-IV

'Who arrived?'
a. Jiñ=jach aj-Maria tsa' jul-i.
FOC $=$ EXCL NC-Maria PRF arrive-IV

'Only Maria arrived.'

b. \# Yik'oty aj-Rosa tsa' jul-i je'el.

and NC-Rosa PRF arrive-IV also

'And Rosa arrived too.' (Infelicitous after saying (15a))

The bimorphemic jiñ=jach 'only', though synonymous with =jach in some contexts, is restricted in the same way as jiñ, i.e., not licensed over numerals (16a) or PPs (16b).

a. $\quad$ Jiñ =jach juñ-k'ej k-om- $\varnothing \quad$ waj.
FOC=EXCL one-CL A1-want-B3 tortilla

Intended: 'I want only one tortilla.'

b. * Jiñ=jach tyi Palenque tsa' k'oty-i- $\varnothing$.

FOC $=$ EXCL PREP Palenque PRF arrive-IV-B3

Intended: 'He arrived only to Palenque.'

This pattern indicates that for jiñ =jach, the semantic content of exclusivity is provided by the morpheme $=j a c h$, but selectional requirements come from jiñ. We argue that this parallels the distribution of English only and just: only is more restricted, always requiring focus, while just exhibits a wider range of uses. A summary of the meaning and distribution of jiñ, =jach and jiñ $=j a c h$ is given in Table 1 .

\begin{tabular}{llllll} 
& Meaning & & Occurs with: & \\
& Exclusive & Focus & NPs & Numerals & PPs \\
\hline jin & & $\checkmark$ & $\checkmark$ & & \\
=jach & $\checkmark$ & & $\checkmark$ & $\checkmark$ & $\checkmark$ \\
jiñ =jach & $\checkmark$ & $\checkmark$ & $\checkmark$ & & \\
\hline
\end{tabular}

Table 1: Meaning and distribution of jiñ, =jach, and jiñ $=j a c h$

As summarized in Table 1, both jiñ =jach and =jach function as exclusives. Both jiñ and jiñ jach are restricted by definiteness and focus. We argue that the morpheme jiñ is contributing the definiteness restriction and the =jach morpheme is contributing exclusivity. In the following section, we provide a compositional analysis building the meaning of jiñ $=j a c h$ from these two morphemes. We then provide further evidence for =jach as an exclusive marker even when separated from focus by discussing its use in emphatic and unexplanatory contexts. 


\section{Morphosemantic compositionality.}

3.1 FORMALISM. In this paper, we adopt and modify a version of the morphosemantic framework developed in Wiegand 2017, 2018, which decomposes exclusive operators into a core exclusive meaning and additional restrictions. In that framework, variation among exclusives is attributed to the presence or absence of additional covert morphological restrictions. Therefore, all exclusives are predicted to share the 'core' exclusive meaning, which is given in (17).

$$
\llbracket \operatorname{EXCL} \rrbracket=\lambda C_{\leq} \cdot \lambda p \cdot \lambda w \cdot \forall q\left[\left(q \in C_{\leq} \wedge w \in q\right) \rightarrow p \leq q\right] \quad \text { (Wiegand 2017, 2018) }{ }^{7}
$$

The formulation in (17) is essentially the semantics standardly assumed for only in that the use of an exclusive asserts that the prejacent is the strongest true proposition among its alternatives (Rooth 1992; Chierchia 2013). However, Wiegand (2018) departs from standard accounts in arguing that EXCL is better described as the semantic entry for just, while only is more complex and thus contains additional morphosemantic information beyond EXCL.

In most standard accounts, exclusives like only operate over propositions by means of association with focus (Rooth 1992). In English, this requires that there be a distinguished element within the utterance marked by a particular prosodic focus contour. Given this focus structure, operators like only quantify over alternative propositions with respect to this focused element.

As shown in the (18), depending on the location of the focus intonation, only quantifies over completely different alternative sets of propositions.
a. Mary only introduced [Foc John] to Sue.
b. Mary only introduced John to [Foc Sue].
c. Mary only [Foc introduced] John to Sue.

In (18a), the alternative set is triggered by John, so only quantifies over propositions of the form 'Mary introduced X to Sue'. In (18b), on the other hand, the focus on Sue results in quantification over propositions of the form 'Mary introduced John to X', and in (18c), the quantification is instead over propositions ranging over ditransitive predicates, 'Mary X'd John to Sue'. The presence of the focus is necessary in order to determine the actual interpretation of the string 'Mary only introduced John to Sue'.

However, unlike only, English just can show exclusivity even when it does not associate with focus, exemplified with the 'unexplanatory' reading where it quantifies over causes or explanations (19-20) (examples taken from Wiegand (2018)).

(19) I was sitting there and the lamp just broke! I don't know what happened.

\footnotetext{
${ }^{7}$ This is equivalent to most standardly adopted lexical entries for English only (Rooth 1992). The main difference is the inclusion of the $C_{\leq}$argument, which represents the ordered pair $\langle C, \leq\rangle$ of an alternative set $C$ and an ordering $\leq$ on $C$. In standard Roothian semantics, $\leq$ would be entailment $(\subseteq)$; however, other contextually provided orderings are needed to capture the evaluative readings of exclusives like merely.
} 
(20) Context: Cordelia and Harmony are at the top of a staircase. Suddenly, Harmony jerks backwards and falls down the stairs. (Later revealed that an invisible girl had pushed her.)

Principal Snyder: ... What happened?

Cordelia: She fell. She, she, we were standing at the top of the stairs and she just fell! All by herself!

Harmony: No! I was pushed!

(Buffy the Vampire Slayer, S1E11)

In (19), the inclusion of just indicates that the speaker does not know the cause or explanation for the lamp breaking. Likewise, in (20), Cordelia's use of just indicates that Harmony's fall was, as far she knew, uncaused. In both of these cases, just does appear to be acting as an exclusive, as its contributed meaning is a quantificational denial of known causes for a given eventuality. However, there is no focused element in either prejacent that could give rise to the appropriate alternative set $C$ involving such causes. Rather, if we tried to force just to associate with an overt element in the utterance, we would derive the incorrect interpretation 'the lamp broke and nothing more' for (19) and 'she fell and nothing more' in (20).

Importantly, other English exclusives like only cannot be used in contexts like (19) and (20), as shown below in their infelicitous counterparts (21) and (22).

(21) \# I was sitting there and the lamp only broke! I don't know what happened.

(22) \# She only fell! All by herself!

Wiegand $(2017,2018)$ argues that just allows quantification over implicit arguments like causes, while operators like only are restricted to quantify over alternatives derived via association with an overtly focused element in the prejacent. The lack of such a restriction for just allows it to quantify over alternatives that involve covert elements, in particular covert causes. A sample derivation for the alternative computation and contribution of just as EXCL is given below in (23) from Wiegand (2017).

(23) Sample derivation of exclusive semantics for unexplanatory just:

Utterance: The lamp just broke.

$e$ : the event of the lamp breaking

$C=\{e \square$ because $x \mid x$ is a contextually salient potential cause for $e\}$

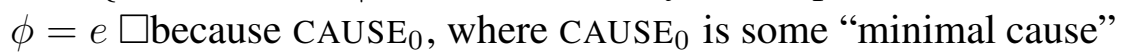

$\llbracket \operatorname{EXCL}(\phi) \rrbracket=\lambda w \cdot \forall q(q \in C \wedge w \in q) \rightarrow \phi \leq q]$

Resulting Paraphrase: "For all explanations $q=$ The lamp broke necessarily because $x$ that are not entailed by $\phi=$ The lamp broke necessarily because CAUSE ${ }_{0}, q \notin w . "$

To capture the differences in meaning between English exclusive operators just and only, Wiegand $(2017,2018)$ proposes a covert morphological operator [FR], which encodes a focus restriction for exclusives like only. The reason that just can quantify over these covert elements while only cannot is attributed to the presence of the [FR] restriction on only, which results in obligatory association with a prosodically focused element in the prejacent. This is a reframing 
of the Focus Principle (Rooth 1992) as a lexical restriction rather than a general rule for all exclusives. The semantic entry for [FR] is given below in (24), where $\partial$ is used for selectional requirement/presupposition.

$$
\llbracket \mathrm{FR} \rrbracket=\lambda F \cdot \lambda K \cdot \lambda q\left[F(K)(q) \wedge \partial\left(K \subseteq \llbracket q \rrbracket^{F}\right)\right]
$$

In this framework, just contributes only the exclusive semantics of [EXCL], while only contributes [EXCL] restricted by [FR]. As such, the addition of [FR] to [EXCL] restricts the meaning to contexts where the focus restriction is met. The compositional morphosemantics proposed for only is given in (25) below.

Only: Composition of EXCL and [FR]:

$$
\begin{aligned}
& \left.\lambda w \cdot \forall q\left[\left(q \in C_{\leq} \wedge w \in q\right) \rightarrow \phi \leq q\right] \wedge \partial\left(C_{\leq} \subseteq \llbracket \phi \rrbracket^{F}\right)\right] \\
& \lambda r . \lambda w . \forall q\left[\left(q \in C_{\leq} \wedge w \in q\right) \overline{\left.\rightarrow r \leq q] \wedge \partial\left(C_{\leq} \subseteq \llbracket r \rrbracket^{F}\right)\right] \quad \phi}\right. \\
& \lambda K . \lambda r . \lambda w . \forall q\left[\left(q \in K \wedge w \in \overline{\left.q) \rightarrow r \leq q] \wedge \partial\left(K \subseteq \llbracket r \rrbracket^{F}\right)\right] \quad C_{\leq}(\phi)}\right.\right. \\
& \text { EXCL: }=\lambda C_{\leq} \cdot \lambda p \cdot \lambda w \cdot \forall q\left[\left(q \overline{\left.\left.q \in C_{\leq} \wedge w \in q\right) \rightarrow p \leq q\right] \quad \text { FR: }=\lambda F \cdot \lambda K \cdot \lambda r[F(K)}(r) \wedge \partial\left(K \subseteq \llbracket r \rrbracket^{F}\right)\right]\right.
\end{aligned}
$$

The lack of restriction on just accounts for its wider distribution of interpretations compared to other English exclusives. These include emphasis, temporal or spacial nearness, mitigation of social implications, and others, as demonstrated in (26) below.

a. I just love your scarf! (emphasis)

b. That fish was just gigantic! (emphasis)

c. I'm just finishing my homework. (temporal recency)

d. You have something just below your eye. (spacial nearness)

e. I'm just saying... (social mitigation)

In the framework presented, the availability of these uses of just is due to the lack of the [FR] restriction present with other exclusives. This framework nicely captures the distribution of just compared to other English exclusives; however, it does heavily rely on the existence of morphological complexity covertly present with other exclusives. While this remains somewhat stipulative for English, the distribution of exclusive operators in Ch'ol and their transparent morphology provide crucial supporting evidence for the structure proposed for English. We will argue that Ch'ol jiñ performs a similar function to the covert [FR] in English, while the freer distribution of =jach, like just, is closer to the bare semantics of EXCL. This Ch'ol data therefore constitutes strong evidence in favor of the idea that exclusivity need not be tied to focus structures. Furthermore, extended uses of =jach indicate that exclusivity when not interacting with focus can give rise to a number of extended discourse and pragmatic effects.

3.2 ApPlying the Formalism to $\mathrm{CH}^{\prime} \mathrm{OL}$. We analyze the data in Ch'ol similarly to the semantics given for English exclusives in the previous section, repeated below in (27). 
a. $\llbracket \mathrm{EXCL} \rrbracket=\lambda C \cdot \lambda p \cdot \lambda w \cdot \forall q[(q \in C \wedge w \in q) \rightarrow p \leq q]$

b. $\llbracket \mathrm{FR} \rrbracket=\lambda F \cdot \lambda K \cdot \lambda q\left[F(K)(q) \wedge \partial\left(K \subseteq \llbracket q \rrbracket^{F}\right)\right]$ (focus restriction on only)

c. $\left.\llbracket \mathrm{EXCL}+\mathrm{FR} \rrbracket=\lambda C \cdot \lambda p \cdot \lambda w \cdot \forall q[(q \in C \wedge w \in q) \rightarrow p \leq q] \wedge \partial\left(C \subseteq \llbracket p \rrbracket^{F}\right)\right]$

In English, the [FR] morpheme is necessarily covert, but we argue that jiñ in Ch'ol carries overtly some of the semantic content that [FR] carries covertly in English. However, for Ch'ol, we need more than the restriction that the alternative set be a subset of the focus alternatives, as $j i \tilde{n}=j a c h$ is restricted by definiteness as well. Since the focus particle jin is also restricted in this way, this restriction must be part of the semantics jiñ , rather than general exclusivity in Ch'ol.

We take the restriction to definite elements for quantification to be a precondition that the focused element be of type $e$, i.e., belong to the domain of individuals. As the formalism stands now, however, we do not have access to the focused element inside the proposition $p$. Therefore, we are not able to restrict jin to compose only with arguements of type $e$.

Thus we adopt a structured meaning approach from von Stechow (1991) to replace $p$ in (27), which allows us to target focused elements and restrict their semantic type. According to this framework, the propositional objects are defined as an ordered pair, the composition of which yields the traditional proposition $p$.

a. Structured propositions for focus von Stechow (1991)

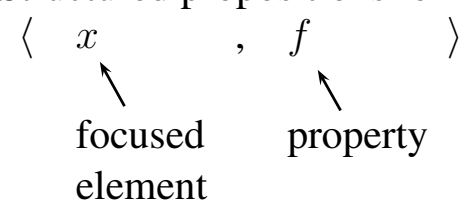

b. Mary saw [FoC John ].

$\langle J, \lambda x[\operatorname{see}(x)(M)]\rangle$

c. [FoC Mary ] saw John.

$\langle M, \lambda x[\operatorname{see}(J)(x)]\rangle$

As shown above, the structured proposition framework retains the focused element as part of the semantic denotation of a proposition. As such, depending on the location of the focus in a sentence like Mary saw John, we have a different structure for the focus on Mary than for the focus on John, despite the fact that the composition of function and argument in both cases yields the same ordinary proposition.

Given this structured proposition approach, we can easily get back the original proposition from (27a), by applying the property $f$ to the focused element $x$, which yields the ordinary proposition $p$ in (27a). We then take =jach in (29) to be identical to (27a), simply rephrased using the structured proposition formalism from (28a), in order to retain access to the focused element. For simplicity, we abbreviate $f(x)$ with $p$.

$$
\llbracket=j a c h \rrbracket=\lambda C \cdot \lambda\langle x, f\rangle \cdot \lambda w \cdot \forall q . \forall y[(q=f(y) \wedge q \in C \wedge w \in q) \rightarrow p \leq q], \text { where } p=f(x)
$$

We propose that jiñ is exactly like [FR], except it also contains a requirement that the focused element be of type $e$ in (30), as shown in the underlined addition to the lexical entry below.

$$
\llbracket j i \tilde{n} \rrbracket=\lambda F \cdot \lambda C \cdot \lambda\langle x, f\rangle\left[F(C)(\langle x, f\rangle) \wedge \partial\left(C \subseteq \llbracket p \rrbracket^{F} \wedge \underline{x \in D_{e}}\right)\right]
$$


Finally, the semantics and selectional requirements of bimorphemic jiñ =jach are thus the result of ordinary function application of jin and =jach, given below in (31) and shown in the tree in (32).

$$
\begin{aligned}
& \llbracket j i \tilde{n}=j a c h \rrbracket=\llbracket j i \tilde{n} \rrbracket(\llbracket=j a c h \rrbracket)= \\
& \lambda C \cdot \lambda\langle x, f\rangle . \lambda w . \forall q . \forall y\left[[(q=f(y) \wedge q \in C \wedge w \in q) \rightarrow p \leq q] \wedge \partial\left(C \subseteq \llbracket p \rrbracket^{F} \wedge x \in D_{e}\right)\right]
\end{aligned}
$$

jiñ =jach: Composition of $[=j a c h]$ and $[j i \tilde{n}]$ :

$$
\left.\lambda w . \forall q\left[\left(q \in C_{\leq} \wedge w \in q\right) \rightarrow \phi \leq q\right] \wedge \partial\left(C_{\leq} \subseteq \llbracket \phi \rrbracket^{F} \wedge \underline{x \in D_{e}}\right)\right]
$$

$$
\lambda r . \lambda w . \forall q\left[\left(q \in C_{\leq} \wedge w \in q\right) \rightarrow r \overline{\left.\leq q] \wedge \partial\left(C_{\leq} \subseteq \llbracket r \rrbracket^{F} \wedge \underline{x \in D_{e}}\right)\right] \quad \phi}\right.
$$

$$
\lambda K . \lambda r . \lambda w . \forall q\left[(q \in K \wedge w \in q) \rightarrow \overline{\left.r \leq q] \wedge \partial\left(K \subseteq \llbracket r \rrbracket^{F} \wedge \underline{x \in D_{e}}\right)\right] \quad C_{\leq}(\phi)}\right.
$$

$j i \tilde{n}:=\lambda F . \lambda C \cdot \lambda\langle x, f\rangle\left[F(C)(\langle x, \bar{f}\rangle) \wedge \partial\left(C \subseteq \llbracket p \rrbracket^{F} \wedge \underline{x \in D_{e}}\right)\right] \quad=j a c h:=\lambda C_{\leq} \cdot \lambda p \cdot \lambda w . \forall q\left[\left(q \in C_{\leq} \wedge w \in q\right) \rightarrow p \leq q\right]$

Under this approach, the exclusive interpretation of jiñ =jach as well as its restriction to elements of type $e$ are easily predicted as a result of this composition.

As currently formulated, jin is required to combine with another operator $F$ in (30). When it combines with $=j a c h$, this yields the correct result with the semantics for jiñ=jach. However, this approach requires an additional operator so that jin can occur in isolation without combining with $=j a c h$. We propose that this is an optional identity function that is inserted freely when jiñ is modifying its proposition directly.

In summary, we argue that in Ch'ol, the exclusivity of jiñ =jach comes from $=j a c h$, while the selectional restrictions come from jiñ. Given this analysis, we expect =jach to occur in environments where the selectional restrictions are not met, which is borne out in the data in the following section.

4. Further evidence for separating exclusivity from focus. In addition to places where definiteness isn't met that were discussed earlier, further evidence for analyzing (27a) as the semantics of just and =jach comes from the additional parallels between these operators. =Jach appears as an intensitifier in (33a) and an unexplanatory exclusive in (33b), paralleling the English in $(34 a-b)$.

a. Uts'aty=jach aw-otyoty. nice $=\mathbf{E X C L}$ A2-house

'Your house is so nice.'

b. Che'=jach tsa' jul-i.

PART $=$ EXCL PRF arrive-IV

'Just like that he arrived.'

(34) a. Your house is just gorgeous!

b. The man just appeared!

${ }^{8}$ In this case, $=$ jach is in its phonetically reduced form [haf]. This parallels usages of 'just' [dzs] as an exclusive marker separate from focus. 
In (33a) above, =jach exhibits an intensifying function on the predicate uts'aty 'nice'. This is quite reminiscent of the behavior of English just as an intensifier in (34a). Likewise, in (33b), =jach expresses suddenness or unexplainability, similar to unexplanatory uses of just (Wiegand 2017, 2018).

In cases like (33b), it is easy to see how this is expressing an exclusive semantics under the assumption that =jach can quantify over covert elements like explanations. For (33a), the exclusivity is less apparent; however, given how closely this parallels the behavior of just, which is also exclusive, we argue that this constitutes compelling evidence that this use of =jach is underlyingly exclusive. ${ }^{9}$ We leave the details of the analysis of intensifying uses of =jach to future work.

Furthermore, it is also clear that in both of the examples above, =jach does not quantify over alternatives derived from one of the elements in the sentence. This follows from our analysis of the morphosemantics of Ch'ol exclusives, as the restriction to association with a focused element comes from jiñ, which is not present in these examples.

5. Conclusions and future directions. The data discussed in this paper provide strong evidence that exclusives when dissociated from focus can result in a variety of discourse effects beyond basic exclusivity, including intensification and mitigation of social implications. Overall, these data constitute compelling crosslinguistic support for separating the meaning attributed to exclusive operators like only into smaller components, each of which contribute a portion of exclusive semantics in general.

This framework also predicts that other morphologically rich languages should exhibit compositionality between exclusive operators. While some languages may resemble the distribution we have documented in Ch'ol, it is also likely that we will observe variation in how exclusive operators are morphologically combined. For example, other languages may involve a composition of morphemes that contribute different restrictions.

Even in English, there is more variation in meaning among exclusive operators than what has been discussed here. For example, unlike both only and just, merely is restricted to operate over alternatives that are ordered by a non-entailment, or 'evaluative', scale (Beaver \& Clark 2008; Coppock \& Beaver 2013). As such, merely is licensed when the prejacent it modifies is valued low on a scale, but infelicitous when its prejacent is valued high on that scale. This contrasts with only and just, which are licensed as long as an entailment matrix can be constructed. This is demonstrated below in (35).

(35) a. Colleges will only look at people who have fewer than five disciplinary infractions, which is great for me, because I \#merely/ $\checkmark$ only/ $\checkmark$ just have two!

b. Those guys will only let you join their club if you have more than five disciplinary infractions, which is bad for me, because I $\checkmark$ merely $/ \checkmark$ only $/ \checkmark$ just have two. (Wiegand 2017)

In order to account for this, Wiegand (2018) proposes an additional operator that restricts the ordering on the alternative set. As such, for English, just is the least morphologically complex,

\footnotetext{
${ }^{9}$ The parallel goes beyond English as well. For example, in Hebrew, pashut 'simple/simply' behaves as an exclusive in some contexts but an intensifier in others.
} 
followed by only with [FR], followed by merely, which utilizes both [FR] and the evaluativity ordering restriction.

This ordering restriction is also observed in Hebrew for exclusive stam, translated as 'merely'/ 'just' (Orenstein \& Greenberg 2010; Orenstein 2015). This is shown below in (36), where stam is not licensed where rak 'only' is.

(36) hu rak/\#stam zaxa [be-pras Nobel $]_{F}$ he only/stam won [in-prize Nobel $]_{F}$ 'He only/stam won the Nobel Prize.'

(Orenstein 2015; 101)

However, unlike English merely, which would also contain the [FR] operator, stam is free to associate with alternatives that are not derived via association with focus, as shown below in (37).

kibalti Saon, ha-beaya hi Se-ze STAM Saon!

Got.I watch the.problem she that.it STAM watch

'I got a watch. The problem is that it's STAM a watch!'

(Orenstein 2015; 103)

As discussed in Orenstein 2015, the alternatives for (37) involve types of watches, rather than alternative types of objects to the watch. While different than the observed behavior of just, this nonetheless shows that stam, like just, does not have the [FR] operator. So, stam has the ordering restriction like merely, but unlike merely, does not have the [FR] operator. This demonstrates that languages may vary in the combination of restrictions placed on particular exclusive operators; therefore, we predict that some languages with more transparent morphology should overtly show the composition of these different kinds of restrictions. For Ch'ol in particular, we have yet to determine whether any of the exclusives we have identified are restricted to non-entailment scales in the same way as English merely and Hebrew stam.

However, during our fieldwork we have found several other combinations of morphemes that involve =jach, each with an exclusive interpretation. One of these is given below in (38) where another particle with exclusive meaning, tyo'ol, occurs with =jach. This example resembles quite closely the interpretation of Hebrew stam in (37).

(38) Translation for 'it's just a watch' with the meaning that is is not that nice of a watch Tyo'ol-reloj=jach. TYO'OL-SP: watch=EXCL

'It's just a watch.'

Another exclusive is $k o=j a c h$, which seems to parallel the meaning of =jach and jiñ $=j a c h$.

Ko=jach aj-Maria tsa' jul-i.

KO=EXCL NC-Maria PRF arrive-IV

'Just Maria arrived.'

In future research, we want to continue to investigate these and other combinations of morphemes with =jach in Ch'ol that result in other types of meanings. This includes the question of whether those include the depreciatory meaning associated with merely and stam or new restrictions that have not been discussed for other languages. This may provide insight into previously undocumented restrictions cross-linguistically, and could open up new research questions in the lexical semantics of exclusive operators, as well as the generation of alternative sets. 


\section{References}

Aissen, Judith. 1992. Topic and focus in Mayan. Language 68(1). 43-80. http://dx.doi.org/10.2307/416369.

AnderBois, Scott. 2012. Focus and uninformativity in Yucatec Maya questions. Natural Language Semantics 20(4). 349-390. http://dx.doi.org/10.1007/s11050-012-9084-3.

Beaver, David \& Brady Z. Clark. 2003. Always and only: Why not all focussensitive operators are alike. Natural Language Semantics 11. 323-362. http://dx.doi.org/10.1023/A:1025542629721.

Beaver, David \& Brady Z. Clark. 2008. Sense and sensitivity: How focus determines meaning. Oxford: John Wiley \& Sons. http://dx.doi.org/10.1002/9781444304176.

Chierchia, Gennaro. 2013. Logic in grammar: Polarity, free choice, and intervention. Oxford: Oxford University Press. http://dx.doi.org/10.1093/acprof:oso/9780199697977.001.0001.

Clemens, Lauren, Jessica Coon, Carol-Rose Little \& Morelia Vázquez Martínez. 2017. Focus in Ch'ol. Presented at The Society for the Study of the Indigenous Languages of the Americas (SSILA) 2017.

Clemens, Lauren Eby \& Jessica Coon. Forthcoming. Deriving verb-initial word order in Mayan. Language TBD.

Coon, Jessica. 2010. VOS as predicate fronting in Chol. Lingua 120(2). 354-378. http://dx.doi.org/10.1016/j.lingua.2008.07.006.

Coppock, Elizabeth \& David Beaver. 2011. Sole sisters. In Neil Ashton, Anca Chereches \& David Lutz (eds.), Semantics and Linguistic Theory (SALT), vol. 21, 197-217. http://dx.doi.org/10.3765/salt.v0i0.2615.

Coppock, Elizabeth \& David Beaver. 2013. Mere-ology. In Anamaria Fălău ş (ed.), Alternatives in semantics, 150-173. London: Palgrave Macmillan UK. http://dx.doi.org/10.1057/9781137317247.

England, Nora. 1991. Changes in basic word order in Mayan languages. International Journal of American Linguistics 57. 446-86. http://dx.doi.org/10.1086/ijal.57.4.3519735.

Little, Carol-Rose, Morelia Vázquez Martínez, Lauren Clemens, \& Jessica Coon. 2016. Codificación del enfoque en el habla semi-natural en ch'ol. Presented at Form and Analysis in Mayan Linguistics (FAMLi) 4 in Valladolid, Mexico.

Orenstein, Dina. 2015. A family of exclusives in Hebrew. In Miriam Kaeshammer \& Philip Schulz (eds.), Proceedings of the European Summer School in Logic, Language and Information ESSLLI, vol. 27, 96-106.

Orenstein, Dina \& Yael Greenberg. 2010. The semantics and focus sensitivity of the Hebrew (unstressed) stam. In Yehuda N. Falk (ed.), Proceedings of Israel Association for Theoretical Linguistics (IATL), vol. 26, .

Rooth, Mats. 1992. A theory of focus interpretation. Natural Language Semantics 1(1). 75-116. http://dx.doi.org/10.1007/BF02342617.

von Stechow, Arnim. 1991. Focusing and backgrounding operators. In Werner Abraham (ed.), Discourse particles, 37-84. Benjamins Amsterdam. http://dx.doi.org/10.1075/pbns.12.04ste. 
Vázquez Álvarez, Juan Jesús. 2011. A grammar of Chol, a Mayan language: University of Texas Austin PhD thesis.

Wiegand, Mia. 2017. Morphosyntax of exclusives and the underspecificity of just. In Julia Nee, Margaret Cychosz, Dmetri Hayes, Tyler Lau \& Emily Remirez (eds.), Proceedings of Berkeley Linguistics Society (BLS), 351-376. Berkeley, CA.

Wiegand, Mia. 2018. Exclusive morphosemantics: Just and covert quantification. In Wm. G. Bennet et al (ed.), Proceedings of the West Coast Conference on Formal Linguistics (WCCFL), vol. 35, Somerville, MA: Cascadilla Proceedings Project.

Wiegand, Mia. Forthcoming. Alternatives, exclusivity and underspecification: Cornell University dissertation.

Yasavul, Murat. 2013. Two kinds of focus constructions in K'iche'. In Todd Snider (ed.), Semantics and Linguistic Theory (SALT), vol. 23, 611-632. http://dx.doi.org/10.3765/salt.v23i0.3161. 